\title{
The diaspora of radiologists in a quest for fellowships - an easy way out, or is there a gap in our training programmes?
}

\section{Savvas Andronikou MB BCh, FCRad (D)SA, FRCR (Lond) \\ Head: Department of Paediatric Radiology Red Cross War Memorial Children's Hospital, University of Cape Town and Institute of Child Health}

The option of training as a fellow in another country is being entertained more frequently by radiologists who have just completed their training in South Africa. Is this just fashionable, a vehicle for immigration, or is there justification for this behaviour? This has become a personal issue for me recently as I, too, am about to embark on a fellowship in paediatric radiology in Melbourne, Australia.

What is a fellowship then? I have no definition for you, but this is the broad idea: Once a registrar has graduated as a specialist radiologist with good general skills there is no official training programme for further sub/superspecialisation in a specific field. Such fields include cross-sectional imaging, neuroradiology, muskuloskeletal radiology, paediatric radiology and even more refined areas such as paediatric neuroradiology.

South African graduates have proved beyond doubt that our general training is of the highest standard and regional hospitals abroad are regularly impressed by our wide range of skills. In contrast to American graduates in particular, we lack expertise in certain fields, especially those involving magnetic resonance imaging (MRI), complex ultrasound techniques and mammography. Even in interventional radiology where many of our registrars have extensive hands-on experience, we probably lack the details of a formal training and definitely suffer the consequences of budget-related technological inexperience. This is all the more topical with the acquisition of new MRI units in the academic departments of the Western Cape where such knowledge is now to be put to use.

A fellowship offers a postgraduate radiologist the opportunity to attain expertise in a field of personal choosing. Such posts are usually offered and sponsored by universities that have a resident expert with skill and expertise in a particular field of radiology. The candidate is considered favourable when not only is he/she to benefit personally because of an inclination or desire to attain the expertise, but also when his/her country of origin has a need. Fellows are paid salaries and are incorporated in the host department's daily functioning, but they are also required to enter the full training programme to learn and teach others. Candidates are expected to apply themselves fully and to engage in the running research programmes of their mentors. Such fellowships extend from 1 to 2 years, after which time candidates can be considered experts in their fields of choice. They are then 
expected to return to their countries of origin, pass on knowledge and apply themselves to patient needs. With that in mind, a prospective fellow should select his/her field, a reputable institution offering fellowships, and even a renowned radiologist of his/her choosing to learn from.

The other side of the coin is that fellowships have created an avenue for radiologists to escape the uncertain social and health-related future of South Africa. Indeed, a fellowship is often a prerequisite for entry into consultant posts in the USA, Canada and the UK. Currently seven Cape Town graduates have already or are about to enter fellowship posts in the above countries. Let us pray that they (including yours truly) will return to South Africa with the expertise that is desperately needed, and let us hope that the health administration recognises that radiology is an indispensable service requiring not only expensive technologically advanced equipment, but also highly specialised staff capable of using it. It's a catch-22 situation in which South Africa needs us to seek knowledge abroad, which in turn makes us less likely to return.

\section{Savvas Andronikou}

Editor 